\title{
Paying Attention to Intention to Transfer in Faculty Development Using the Theory of Planned Behavior
}

\author{
Tejinder Singh ${ }^{1, *}$, Willem De Grave ${ }^{2}$, Jaishree Ganjiwale ${ }^{3}$, Arno Muijtjens ${ }^{4}$, Cees van der Vleuten ${ }^{5}$ \\ ${ }^{1}$ Christian Medical College, Ludhiana, India \\ ${ }^{2}$ Department of Educational Development and Research, MD Maastricht, the Netherlands \\ ${ }^{3}$ Pramukh Swami Medical College, Charutar Arogya Mandal, Karamsad, India \\ ${ }^{4}$ Faculty of Health, Medicine and Life Sciences, Maastricht University, MD Maastricht, the Netherlands \\ ${ }^{5}$ Department of Educational Development and Research, MD Maastricht, The Netherlands \\ *Corresponding author: drtejinder22@gmail.com
}

Received April 17, 2014; Revised May 26, 2014; Accepted May 29, 2014

\begin{abstract}
Context: Only a small proportion of knowledge and skills acquired during faculty development is actually applied on the job, leading to poor transfer of training. This results in wastage of training efforts. The present study was designed to predict the intention to transfer after participation in a faculty development workshop using theory of planned behavior (TPB). Methods: A questionnaire was designed covering direct measures of the TPB constructs viz. 'attitudes towards behavior', 'perceived control over behavior' and 'subjective norms', which was used to predict intention to transfer. Three hundred twenty four mid-level medical educators took the survey. Results: Respondents had a mean of $10.59 \pm 7.39$ and $5.25 \pm 5.24$ years of experience of teaching undergraduate and postgraduate classes respectively. The model accounted for $41 \%$ change in intention to transfer, with standard regression co-efficient equal to 0.51 for 'attitudes towards behavior', 0.21 for 'perceived control over behavior' and 0.07 for 'subjective norm'. Discussion: Attitudes towards behavior and perceived control over behavior had greater influence over intention to transfer compared to subjective norms. The faculty development programs should focus on developing positive attitudes and perceived control over behavior of the participants.
\end{abstract}

Keywords: faculty development, training, theory of planned behavior, intention to transfer, transfer of training, attitudes

Cite This Article: Tejinder Singh, Willem De Grave, Jaishree Ganjiwale, Arno Muijtjens, and Cees van der Vleuten, "Paying Attention to Intention to Transfer in Faculty Development Using the Theory of Planned Behavior.” American Journal of Educational Research, vol. 2, no. 6 (2014): 361-365. doi: 10.12691/education-2-6-5.

\section{Introduction}

A large chunk of research on faculty development effectiveness so far has focused on the lower 2 levels of Kirkpatrick [1] i.e. reactions and learning and there is a paucity of research [2] on application of newly acquired knowledge and skills as well as its effect on the organization. Although there are no reports for this in the field of faculty development in health professions education, the reported transfer of knowledge and skills learnt at training in general is less than $50 \%$ [3]. The ultimate objective of faculty development is to change teaching practices to positively influence student learning. This means that faculty development should enable the transfer of learning to the workplace. In this context, increasing attention is being paid to 'transfer of training' in faculty development in many areas including higher education [4].

Transfer of training is said to occur when the knowledge and behavior learned during training is actually used on the job for which it was intended [5]. Cheng \& Hampson [6] have elaborated on the individual and situational variables that can influence transfer motivation and behavior. Individual characteristics, especially locus of control, can influence transfer as well as skill acquisition [7]. People with high self-efficacy [8] and high self-esteem [9] not only learn complex tasks better but also transfer them better. Expected utility of training, especially in near future also affects transfer behavior [10]. Among situational variables, transfer climate- i.e. nature of workplace practices in supporting transfer of training - has been found to have a significant influence [11,12]. In addition, a number of other variables within the situation like support from peers, superiors and subordinates also have an effect on transfer [11,13].

The transfer research has been guided by a number of theories and conceptual frameworks. Prominent among these include the equity theory [14,15], expectancy theory [16] and goal setting theory [17]. These theories are considered a good support to explain the motivation to transfer [18]. While these theories look at the interplay of the individual with the situation, an increasing attention is being paid to the decision role of trainees in the transfer process. Cheng \& Hampson [6] lay a special emphasis on the role of the trainee as being important in deciding the actual transfer of training. The knowledge needs to be 
acquired, it needs to be transferred to the job and that the trainee makes this decision as an intention to do so. This validates the necessity to continue with transfer research using more robust psychological theories like the theory of planned behavior [19]. This will help to turn attention to the role of trainees' intention to transfer. The theory of planned behavior considers behavioral intention as a function of the attitude towards behavior, subjective norm and perceived controlover behavior.

Attitude towards the behavior refers to the positive or negative feelings an individual has towards a particular behavior [19]. It is an attitude that has been conceptualized from the evaluation of the behavior. Attitude towards behavior is a function of one's salient belief about performing the behavior and an evaluation of the outcomes resulting from the behavior [20]. Subjective norm refers to the social pressure an individual has on whether to complete the behavior or not. This is a person's belief that the salient referent thinks he or she should (or should not) perform the behavior. Subjective norm is individual's perception of what most people who are important to him think about that behavior. Perceived Control over Behavior refers to the perceived ease or difficulty of performing the behavior. It refers to the degree to which the individual feels that the performance (or non-performance) of the behavior in question is under his volitional control.

These three components - attitude towards behavior, perceived control over behavior and subjective norms function independently to determine the intention to perform (or not perform). Intention is the immediate antecedent to behavior - serving as an intermediate variable for actual behavior - and has been found to correlate well with actual behavior. The TPB postulates that behavioral intention is the immediate antecedent of volitional behavior. Empirical studies have validated the strength of this intention-behavior link in the TPB model [19]. Beck and Ajzen [21] reported predictability of intentions across 6 months with a correlation of 0.83 with actual behavior. Therefore, behavioral intentions have been considered as a useful outcome variable in most of the TPB studies.

TPB has been applied to a number of behaviors in health and social sciences [22,23]. However, its use in predicting application of new knowledge and skills following participation in faculty development programs, especially in the education of health professions, has been extremely limited. Patterson [24] reported the use of TPB to evaluate a faculty development workshop and found that participants' intention to use the workshop activities correlated significantly with their use. Attitudes towards using these activities were better predictor of their use than the subjective pressures. Casper [25] reported the effectiveness of implementation intentions in increasing the use of practice behaviors. The author used traditional teaching methods in one group, while in the other intention to act was specifically included as a strategy. The group where TPB approach had been used reported higher use of the new skills in their work. Changes in attitudes, subjective norms and perceived control accounted for $12 \%$ variance in the results, whereas knowledge could account for only $1 \%$. Chen (26)used TPB to predict the Taiwanese kindergarten teachers' intention to join an inservice graduate level academic program. Attitudes toward Behavior and Subjective Norm were found to be significantly correlated with the intention to join the program. These findings were used to suggest use of certain strategies to increase the enrollment in the program.

The present cross-sectional study was undertaken to find the relative strength of the three components of TPB (viz. attitudes towards behavior, perceived control over behavior and subjective norms) to predict participants' intention to transfer following participation in a faculty development program.

\section{Methods}

The study used a self-reported questionnaire to assess the utility of TPB constructs to predict self-reported behavioral intention to apply the knowledge and skills acquired during a faculty development workshop. Formal review and waiver were obtained from institutional ethics committee. A total of 324 teachers who had been through a three day faculty development workshop during 2009 to 2012 were administered this questionnaire on the last day of the workshop. The focus of the enquiry was on behavioral intention. The independent variables were attitudes towards behavior, perceived control over behavior and subjective norms while behavioral intention was the dependent variable.

The questionnaire was developed by enrolling 30 faculty members, who were not part of the study group, selected by convenience sampling to include teachers from various departments and different academic levels. They were requested to consider the following statement as a personal commitment pronouncement: "After participating in a faculty development workshop, I would in the course of next three months, apply the new knowledge and skills to my teaching”. They were asked to list its advantages and disadvantages, persons and groups who would approve and disapprove and conditions that would make it easy or difficult when they act. Based on the data so generated, a scale was designed to assess the 3 TPB constructs ( 3 items each) and behavioral intentions (3 items). Each item was to be rated on a 7-point scale, with 1 being the least likely and 7 being the most likely. Reverse scoring was used where needed. The strength of each construct was measured by averaging the item scores for each variable. Items used to measure constructs and there inter-relationship are shown in Table 1. A structural equations model was fitted to validate the questionnaire.

The structural equations model was developed for the four 3-item scales corresponding to the TPB latent variables viz. Attitude towards Behavior (AtB), Subjective Norm (SN), and Perceived Control over Behavior (PCB), and Intention (INT). The model was analyzed using the software package AMOS version 19. The seven indices presented in Table 2 were used to evaluate the model fit. In addition the internal consistency of the scales was tested in a reliability analysis using the statistical package SPSS 19.

\section{Results}

A total of 324 teachers were included in the study, of which 137 (38.8\%) were males. Mean age of the respondents was $37.86 \pm 7.38$ years. They had a mean of 
$10.59 \pm 7.39$ years of experience of teaching undergraduate classes while that of teaching postgraduates was $5.25 \pm$
5.24 years. Mean and standard deviation of items and scale scores are shown in Table 1.

Table 1. Items used to measure constructs and reliability (Cronbach's alpha) of the corresponding scales ( $\mathrm{N}=324$ respondents)

\begin{tabular}{|c|c|c|c|}
\hline Constructs & M & $\mathrm{SD}_{-}$ & alpha \\
\hline Attitude towards Behavior (AtB) & & & 0.78 \\
\hline 1. Overall, I think application of new skills is useful. & 6.60 & 0.624 & \\
\hline 2. Overall, I think application of new skills is extremely good. & 6.58 & 0.606 & \\
\hline 3. Overall, I think application of new skills is pleasant for me. & 6.36 & 0.728 & \\
\hline Subjective Norms (SN) & & & 0.81 \\
\hline 4. People who are important to me, would approve my application of new skills to my teaching. & 6.39 & 0.656 & \\
\hline 5. I feel obliged to apply the new skills to my teaching. & 6.31 & 0.685 & \\
\hline 6. I am expected to apply the new skills to my teaching. & 6.29 & 0.704 & \\
\hline Perceived Control of Behavior (PCB) & & & 0.82 \\
\hline 7. I am confident that I can apply the new skills to my teaching. & 6.13 & 0.819 & \\
\hline 8. Whether I apply the new skills to my teaching is entirely up to me. & 5.97 & 0.863 & \\
\hline 9. For me, application of new skills to my teaching is easy. & 5.57 & 0.757 & \\
\hline Generalized intention (INT) & & & 0.84 \\
\hline 10.I expect to apply the new skills to my teaching. & 6.47 & 0.714 & \\
\hline 11. I intend to apply the new skills to my teaching. & 6.45 & 0.704 & \\
\hline \multicolumn{4}{|l|}{ Excluded from the scale (INT): } \\
\hline 12. I want to apply the new skills to my teaching. & & & \\
\hline
\end{tabular}

The conceptual model was translated into a structural equation model. The relationship between variables was estimated by maximum likelihood estimation.

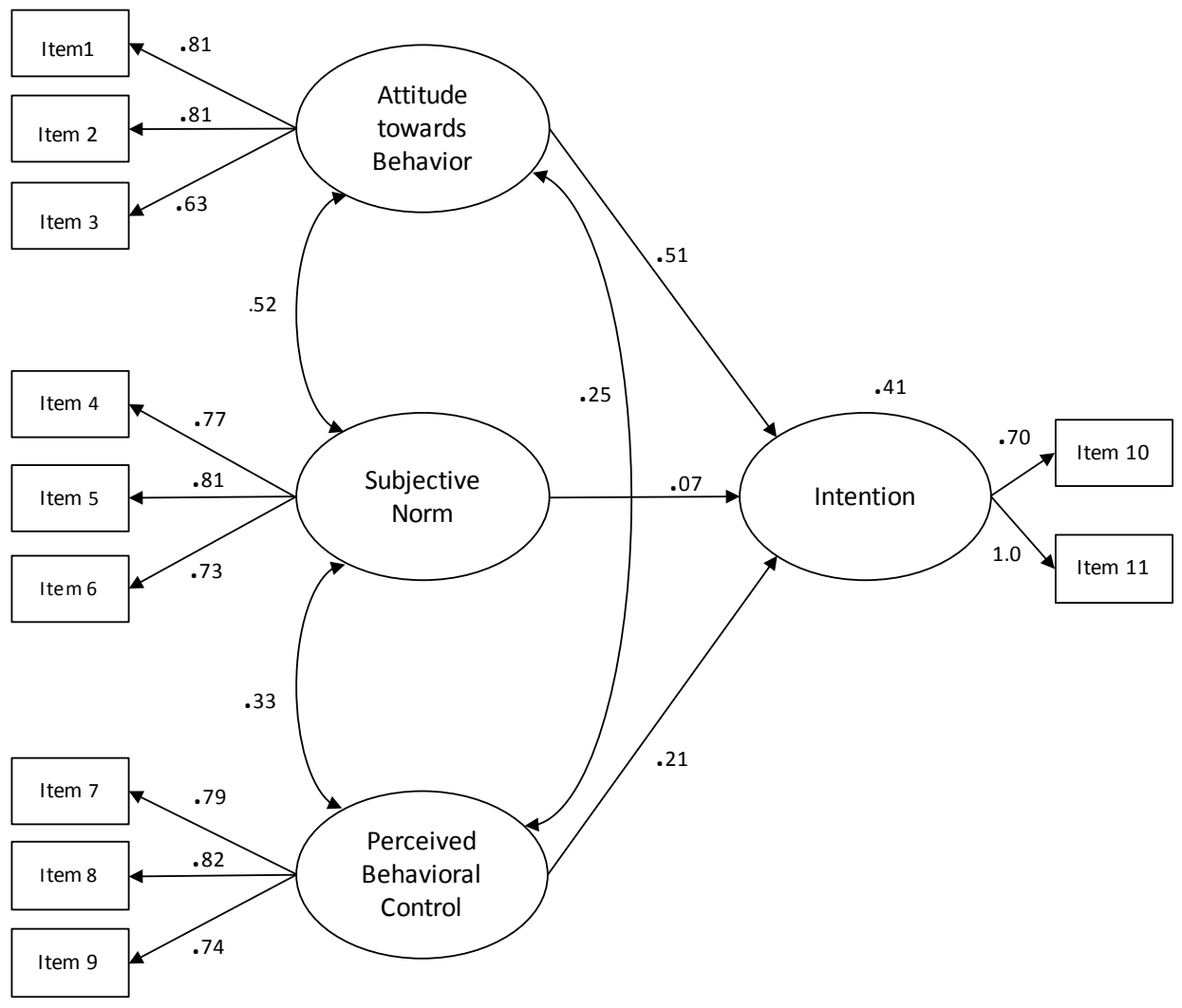

Figure 1. Structural equations model for the TPB latent variables Attitude towards behavior (AtB, 3 items), Subjective norm (SN, 3 items), and Perceived Behavioral Control (PCB, 3 items) as predictors of a fourth latent variable, Intention (INT, 2 items). AtB, SN, and INT explain 41\% of the variance of INT, where AtB has a large contribution (standard regression coefficient (src)=.51), SN has a negligible contribution (src=.07) and PCB a small to moderate contribution ( $\mathrm{src}=.21$ ). For each item the loading on the corresponding latent variable is indicated and at the double arrowed lines the correlation of the independent latent variables is presented

Attitude towards Behavior, Subjective Norm, and Perceived Control over Behavior explained $41 \%$ of the variance of intention, where Attitude towards Behavior had a large contribution (standard regression 
coefficient(src)=.51), Subjective Norm had a negligible contribution (src=.07) and Perceived Control over Behavior a small to moderate contribution ( $\operatorname{src}=.21$ ). All original scales were maintained, except for Intention where removal of item 12 substantially increased the reliability of the scale (Cronbach's alpha increased from 0.74 to 0.84 ) as well as the fit of the model. For the scales of the final model appropriate levels of reliability were obtained (Table 1). The fit of the model in Figure 1 was found to be sufficient, showing acceptable values for the majority of the fit indices (Table 2).

Table 2. Structural equations model for TPB, fit indices, criteria, and fit results for the faculty development TPB data

\begin{tabular}{ccc}
\hline Fit indices & Criterion & TPB model \\
\hline CMIN/DF & $<3$ & 2.83 \\
GFI & $>0.9$ & 0.94 \\
TLI & $>0.9$ & 0.93 \\
CFI & $>0.9$ & 0.95 \\
RMSEA & $<0.08$ & 0.08 \\
Pclose & $>0.5$ & 0.01 \\
RMR & $<0.05$ & 0.03 \\
\hline
\end{tabular}

\section{Discussion}

We used TPB to predict the intention to apply the new knowledge and skills acquired during FD workshops. The model accounted for $41 \%$ change in intention to transfer, with standard regression coefficients equal to 0.51 for 'attitudes towards behavior', 0.21 for 'perceived control over behavior' and 0.07 for 'subjective norm'. All three components were positively related to behavioral intention - of these Attitudes towards Behavior and Perceived Control over Behavior showed a highly significant correlation. In a study by Lee et al [27] attitudes towards behavior had double the influence of subjective norms and three times the effect of perceived control over behavior in deciding use of educational technology. In our study, attitudes towards behavior had 7 times the effect of perceived control and three times the effect of subjective norms in predicting intention to transfer.

It can be argued that acquiring new knowledge and skills is one of the several factors that decide if the participants are going to apply that knowledge. The new knowledge and skills may not be applied if participants do not value them or if people who matter do not favor such application. Delivering FD programs aimed at acquiring knowledge and skills without taking these factors into consideration may limit the utility of such programs. Our findings suggest that although all three constructs had significant predictive power, and as such should be considered when implementing a FD intervention, it appears that one's efforts to promote transfer of training would best be directed toward shaping participants' attitudes and perceived control over new teaching skills. Our findings suggest that the intention to transfer will be stronger if participants develop positive attitudes towards new concepts sought to be implemented and also perceive that they are able to undertake actions to transfer. In other words, what participants value seems to be more important rather than how much they know or what others feel. This is very much in line with the empirical work on 'conceptions' or 'beliefs' on learning and what teachers do in practice $[28,29]$. The TPB has emerged as one of the most influential and a popular conceptual framework for the study of human behavior and considerable literature support is available for the efficacy of the theory as a predictor of both intentions and behavior [30]. Its potential to shape behavioral change by developing appropriate interventions is also being increasingly recognized [31]. There is a lack of such research on transfer of training following faculty development interventions such as a workshop and how to operationalize the variables.

Our results provide inputs regarding design of FD programs, which is also a factor influencing transfer of training. Attitude towards behavior was found to have a stronger influence on intention to transfer. This suggests that participants base their behavioral intentions on the potential benefits of their actions rather than on how much they know or what others think about it. Including information on 'why' an educational method should be used is likely to result in better intentions rather than focusing only on 'how' it should be used. It also appears useful to alter the training strategies to include not only provision of knowledge and skills but also to develop positive attitudes towards intended behaviors. Lack of importance of subjective norms for intentions to transfer may be related to lack of high expectations and/or rewards in the organization for improvement of teaching.

A number of strategies can be adopted during training to strengthen the attitudes towards transfer of new knowledge. Linking faculty development to better training of graduates, improved health of the population and better health manpower retention can be some of the examples $[32,33]$ to help the participants develop positive attitudes. Similarly, using interactive training methods and encouraging the participants to undertake hands-on activities (e.g. designing OSCE stations, writing good quality MCQs) should help to improve perceived control over behavior. Simply using regulations to bring change in instructional delivery, by strengthening subjective norms, may have very little influence on intention to transfer.

There were some limitations to our study. Notwithstanding the strength of past associations between intention and behavior, we looked at behavioral intention rather than at actual behavior. There were also the limitations of self-reports, which have been shown to inflate the variance compared to objective measures. Direct observation of teaching behaviors and/or feedback from students could have helped in looking at actual behaviors. It would also be interesting to look at the actual application of new knowledge and skills acquired by participating in FD programs which have been redesigned to address the TPB variables.

\section{Acknowledgements}

Acknowledgements are due to R Hoogenboom from the School of Health Professions Education, Maastricht University for help in the development of TPB model.

\section{Conflict of interest}

None. 


\section{References}

[1] Kirkpatrick, D. L. (1967). Evaluation of training. In R. L. Craig \& L. R. Bittel (Eds.), Training and Development Handbook (pp. 87112). New York: McGraw Hill.

[2] Steinert, Y., Mann, K., Centen, A., Dolmans, D., Spencer, J., Gelula, M., et al. (2006). A systematic review of faculty development initiatives designed to improve teaching effectiveness in medical education: BEME Guide No. 8. Medical Teacher, 28, 497-526.

[3] Saks, A. M., \&Belcourt, M. (2006). An investigation of training activities and transfer of training in organizations. Human Resource Management, 45, 629-648.

[4] DeRijdt, C., Stess, A., Vleuten, C. P. M. van Der Vleuten, \&Dochy, F. (2013). Influencing variables and moderators of transfer of learning to the workplace within the area of staff development in higher education: Research review. Educational Research Review, 8, 48-74.

[5] Olsen, J. H. J. (1998). The evaluation and enhancement of training transfer. International Journal of Training and Development, 2, 61-75.

[6] Cheng, E. W. L., \&Hampson, I. (2008). Transfer of training: a review and insights. International Journal of Management Reviews, 10, 327-341.

[7] Silver, W. S., Mitchell, T. R., \& Gist, M. E. (1995). Responses to successful and unsuccessful performance: the moderating effect of self-efficacy on the relationship between performance and attribution. Organizational Behavior and Human Decision Process, 62, 289-299.

[8] Ford, J. K., Quinones, D. A., Sego, D. J., \&Sorra, J. S. (1992). Factors affecting the opportunity to perform trained tasks on the job. Personal Psychology, 45, 511-527.

[9] Warr, P., \&Bunce, D. (1995). Trainee characteristics and the outcome of open learning. Personal Psychology, 72, 351-367.

[10] Lim, D. H., \& Johnson, S. D. (2002). Trainee perceptions of factors that influence learning transfer. International Journal of Training and Development, 6, 59-74.

[11] Tracey, J. B., Tannenbaum, S. I., \& Mathieu, J. E. (2001). The influence of individual characteristics and the work environment on varying levels of training outcomes. Human Resource Development Quarterly, 12(1), 5-23.

[12] Xiao, J. (1996). The relationship between organizational factors and the transfer of training in the electronics industry in Shenzhen, China. Human Resource Development Quarterly, 7, 55-73.

[13] Bruke, L. A., \& Baldwin, T. T. (1999). Workforce training transfer: a study of effect of relapse prevention and transfer climate. Human Resource Management, 38, 227-242.

[14] Adams, J. (1963). Towards an understanding of inequity. Journal of Abnormal and Social Psychology, 67, 422-436.

[15] Vroom, V. (1964). Work and Motivation.

[16] New York: Willey Deci, E. (1975). Intrinsic motivation. New York: Plenum.

[17] Locke, E. A. (1968). Towards a theory of task motivation and incentives. Organizational Behavior and Human Performance, 3, 157-189.
[18] Yamnill, S., \& McLean, G. N. (2001) Theories supporting transfer of training. Human Resource Development Quarterly 12(2), 19520.

[19] Ajzen, I. (1991). The theory of planned behavior. Organizational Behavior and Human Decision Process, 50, 179-211.

[20] Chang, M. K. (1998). Predicting unethical behaviour:a comparison of thetheory of reasoned action and the theory of planned behaviour. Journal of Business Ethics, 17, 1825-1834.

[21] Beck, L., \&Ajzen, I. (1991). Predicting dishonest actions using the theory of planned behavior. Journal of Research in Personality. 25, 285-301.

[22] Ceccato, N. E., Ferris, L. E., Manuel, D., \&Grimshaw, J. M. (2007). Adopting health behavior change theory throughout the clinical practice guidelines. Journal of Continuing Education in the Health Professions, 27, 201-207.

[23] Henning, M.A., Ram, S., Malpas, P., Shulruf, B., Kelly, F., \&Hawken, S.J. (2013). Academic dishonesty and ethical reasoning: Pharmacy and medical school students in New Zealand. Medical Teacher, 35, e1211-e1217.

[24] Patterson, R. R. (2001). Using the theory of planned behavior as a framework for the evaluation of a professional development workshop. Microbiology Education, 2, 34-41.

[25] Casper, E. S. (2007). The theory of planned behavior applied to the continuing education of mental health professionals. Psychiatric Services 58, 1324-1329.

[26] Chen, I. J. (2007). Using the theory of planned behavior to understand in-service Kindergarten behavior to enroll in a graduate level academic program Journal of College Teaching and Learning, 4, 13-18.

[27] Lee, J., Cerreto, F., \& Lee, J. (2010). Theory of Planned Behavior and Teachers' Decisions Regarding Use of Educational Technology. Educational Technology \& Society, 13, 152-164.

[28] Williams, E. G., \&Klamen, D. L. (2006). See one, do one, teach one - exploring the core teaching beliefs of medical school faculty. Medical Teacher, 28, 418-424.

[29] Jacobs, J. C., Luijk, S. J. V., Berkel, H. V., Vleuten, C. P. M. van Der Vleuten , Croiset, G., \& Scheele, F. (2012). Development of an instrument (the COLT) to measure conceptions on learning and teaching of teachers, in student-centred medical education. . Medical Teacher, 34, e483-e491.

[30] Armitage, C. J., \& Conner, M. (2001). Efficacy of the theory of planned behaviour: a meta-analytic review. British Journal of Social Psychology, 40, 471-499.

[31] Hardeman, W., Johnston, M., Johnston, D. W., Bonetti, D., Wareham, N. J., \&Kinmonth, A. L. (2002). Application of the Theory of Planned Behavior in behavior change interventions: a systematic review. Psychology and Health, 17, 123-158.

[32] Burdick W.P., Morahan, P.S., Norcini, J.J. (2006). Slowing the brain drain: FAIMER education programs. Medical Teacher 28:631-634.

[33] Burdick, W. P., Morahan, P. S., \& Norcini, J. J. (2007). Capacity building in medical education and health outcomes in developing countries: the missing link. Education for Health, 20. Retrieved from http://www.educationforhealth.net/publishedarticles/article_print_ 65.pdf. 